\title{
Accounting Issues: An Essay Series Part II - Accounts Receivable
}

\author{
Judith A. Laux, (E-mail: JLaux@ColoradoCollege.edu), Colorado College
}

\begin{abstract}
This is the second in a series of articles designed to help academics refocus the introductory accounting course on the theoretical underpinnings of accounting. Intended as a supplement for the principles course, this article connects the asset Accounts Receivable to the essential theoretical constructs, discusses the inherent tradeoffs and measurement dilemmas involved, describes newsworthy examples of "beyond-GAAP accounting," and offers a brief bibliography for further investigation should students or professors choose to research this element in more depth.
\end{abstract}

\section{INTRODUCTION}

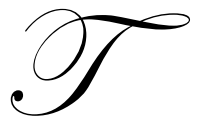

he justification for this series is outlined in "Accounting Issues: An Essay Series—Part I—Cash" [Laux, 2007]. In that article, the asset cash was discussed in terms of its relationship to the various accounting characteristics, displayed once more in the table on the following page. The mountain hiking analogy provides the basis for inspecting the challenges in initially recording transactions, adjusting the accounts, and reporting the elements through financial statements- that is, during the everyday accounting activities ("on the plains"-before the ascent up the mountain even begins), up the "foothills," and finally to the "peak" where we hope economic reality is reflected in such a way that investors and creditors find the information useful in making decisions. We continue in that same spirit, addressing those concepts and issues most closely connected to Accounts Receivable. Should you need a "refresher" on the hierarchy of accounting characteristics, now is the time to revisit the above-referenced article, paying special attention to the section labeled "The Conceptual Framework at a Glance." The next section describes the general accounting approach to receivables and is followed by two sections addressing the conceptual connections and measurement issues most clearly connected to accounts receivable. The final portion presents some of the most intriguing headline stories and related articles for further investigation.

\section{ACCOUNTING FOR RECEIVABLES IN BRIEF}

As the principles of accounting course indicates, accounts receivable occur when customers purchase goods or services with the promise to pay in the future. Normally, the initial transaction is recorded by increasing Accounts Receivable and Revenues by the gross or retail amount. At the end of the accounting period, during the adjusting process, the accountant must determine how many of those receivables will probably be collected in the future, reporting to the statement readers a "net" (collectible) amount that truly represents an asset (an economic resource expected to benefit future periods as the dollars are collected in cash). This "net realizable value" is the difference between the gross amount in the Accounts Receivable account and the balance in Allowance for Bad Debts (a contraasset account), a balance established during the adjusting process typically through one of three estimation approaches-as a percentage of gross Accounts Receivable, through an ageing of accounts receivable, or as a percentage of Sales. While the details of this adjusting process are left to the introductory course, suffice it to say here that (1) it involves an estimate, and (2) that estimate is typically based on past history. The following section will discuss the theoretical ramifications of recording gross accounts receivable and recognizing uncollectible accounts at year-end. 


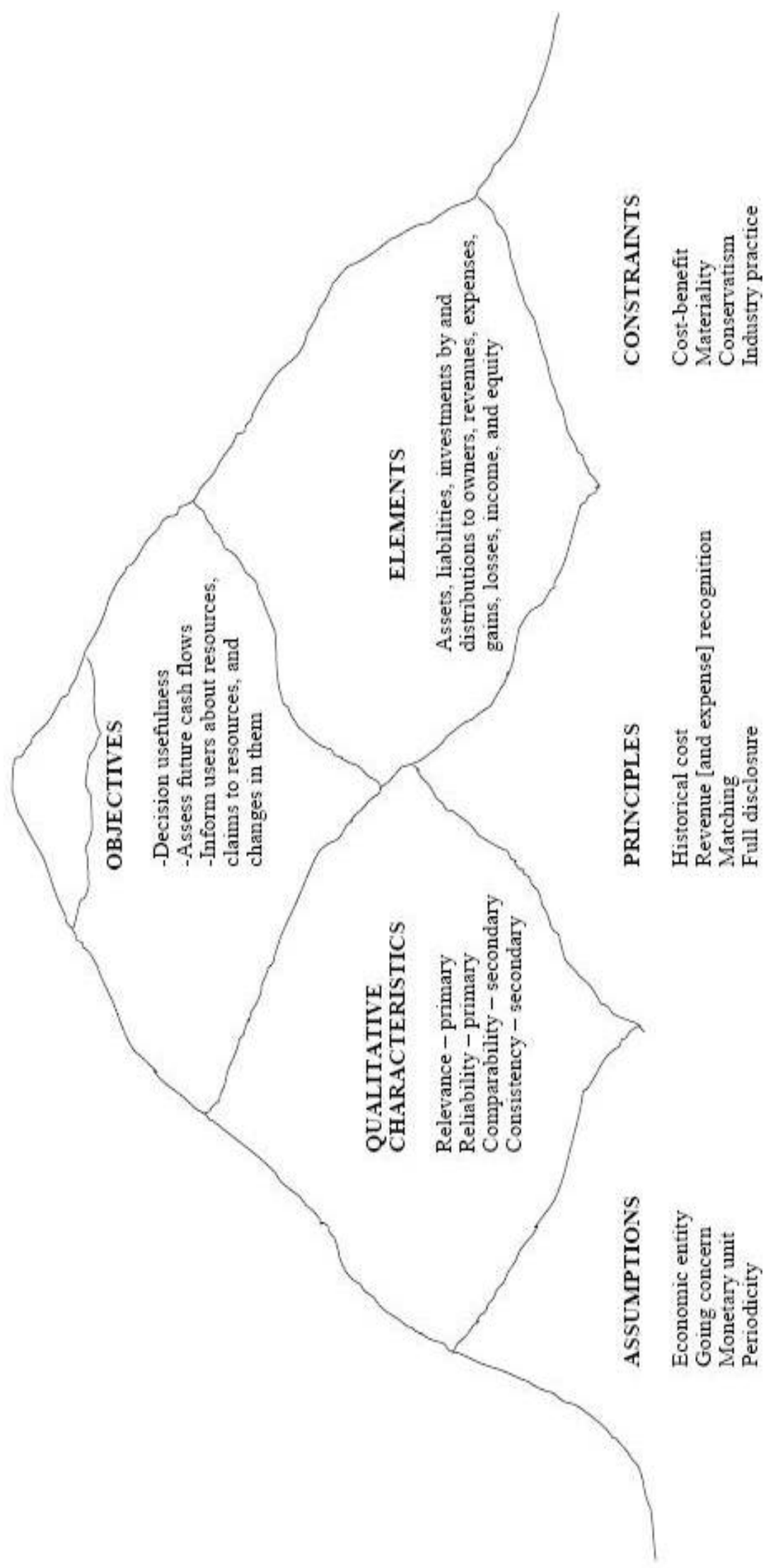




\section{THE CONCEPTUAL FRAMEWORK AND ACCOUNTS RECEIVABLE}

As the illustration on the preceding page indicates, decision usefulness primarily depends on the existence of both relevance and reliability for a reported item. Thus, the balance reported for Accounts Receivable (and the associated Allowance for Bad Debts account) must be important to investors and creditors (able to influence their assessment of past economic events and/or help to predict future cash flows) and be reliably reported. We will cover both of these conceptual connections in turn.

Other than marketable securities (which, in comparison to accounts receivable, ordinarily comprise a small percentage of total assets), receivables from customers are the closest thing to cash for the majority of firms. As such an important asset and element of liquidity, it factors highly in critical measures such as the current ratio, the quick (or acid-test) ratio, and accounts receivable turnover and influences creditor decisions such as extending short-term loans. Future cash flow predictions rely heavily on the absolute amount of and changes in Accounts Receivable, making it score high on the relevance scale.

Financial statement readers rely on net realizable value [Accounts Receivable, at historical cost, less Allowance for Bad Debts (AFBD)] to make a determination about future cash flows; but net realizable value [NRV] relies on an estimate (AFBD), and therefore, reliability is lessened. Thus a trade-off exists between relevance and reliability. Companies can manipulate income by altering estimated uncollectible accounts, and many stories of fraudulent and misleading reporting have made the news in recent years. In other instances, corporate income smoothing techniques have included playing with this estimate, overestimating uncollectible accounts in years in which income is otherwise exceeding estimates and underestimating bad debts in years where income is coming up short. This can also impair comparability over time and from company to company if one entity uses bad debt estimates as a way of smoothing income while another does not succumb to this temptation.

On a related note, companies must use full disclosure in their approach to estimating uncollectible accounts (tell statement readers how they arrive at AFBD) and must not change their general approach from one year to the next, giving the appearance of a high level of consistency. However, a certain latitude is granted in setting the percentages (of gross Accounts Receivable, Sales, or even within the percentages used in the ageing of accounts procedure) that establish the net realizable value, making it possible for companies to skirt true consistency from year to year and impairing the statement reader's ability to assess future cash flows from a given year's net amount. The following section looks at some additional conceptual connections as they relate to measurement of Accounts Receivable.

\section{MEASUREMENT ISSUES AND THEIR CONCEPTUAL CONNECTIONS}

Accounts Receivable analysis really involves two major measurement issues:

- Is the gross receivables amount reflective of real economic transactions or events?

- $\quad$ Is the amount of Allowance for Bad Debts reflective of dollars that will not be collected?

The first relates to revenue recognition and the second to the concepts of expense recognition and matching. Most introductory accounting courses thoroughly cover the critical stage of revenue recognition, making it quite clear that both buyer and seller must fulfill certain requirements before companies should measure and record revenues (and the associated account receivable) formally in the accounting books. Yet it is at this juncture that many "beyond-GAAP" missteps have occurred. (Some of the headliners will be presented in the following section.) Here, on the plains of everyday accounting, accountants can elect or be pressured to advance or even create revenues and receivables, making the associated values premature, overstated, or even fictitious. If the firm has not done its job (fulfilling a service contract or delivering a product with limited right of return) and/or if a customer has not made a believable promise to pay the firm, recognition represents non-GAAP accounting, and the resulting Accounts Receivable are overstated. The firm is not, in fact, better off financially, has no new asset, and does not have the promise of future cash flows. This is the economic reality, and accountants are challenged to reflect that reality. 
In a similar light, accountants must report an amount of AFBD that accurately reflects dollars of receivables that will not be collected, an expense to be recognized as Bad Debts Expense. Since this relies on an estimate, more leeway exists (accountants are not expected to be perfectly accurate), but financial statement users should be able to rely on a good faith effort. That is, accountants should offer their best judgment based on available history and other facts or prognostications (such as a widely recognized economic recovery or recession) and should not attempt to bias that estimate either upward or downward. This concept is referred to as "neutrality" and enhances the primary characteristic of reliability. Furthermore, the allowance method of accounting for bad debts represents an attempt to adhere to the matching principle so that the expense associated with uncollectible accounts is recorded in the same accounting period as (and thereby "matched" with) the associated revenues.

Certain constraints also relate to accounting for Accounts Receivable. A company can reject the preferred approach just noted (estimating uncollectible amounts and establishing a contra-asset account) if it has a history of very few uncollectible accounts (low bad debt expense). This is the concept of materiality, which states that GAAPbased approaches can be dispensed with if the difference in income (and/or assets, in this case) is not significant. Because the allowance method requires the extra effort of estimating uncollectible accounts and results in more complex accounting, the cost might be perceived as exceeding the benefit derived from the added accuracy. Thus the cost-benefit constraint plays a role. Finally, when faced with a range of defensible (logical) values for assets such as accounts receivable, the concept of conservatism encourages accountants to state the net amount (net realizable value-NRV) at the lower end of that acceptable range. For example, if an accountant believes between $\$ 1000$ and $\$ 2000$ of the $\$ 50,000$ of gross receivables might be uncollectible, he or she should move towards the $\$ 2000$ end, making the reported NRV closer to $\$ 48,000$ than $\$ 49,000$. Note that conservatism does NOT encourage an understatement of Accounts Receivable to be collected. It simply suggests that, within an acceptable range, one should move to the lower end for assets. Remember, the goal is to reflect economic reality, not to mislead investors and creditors into believing the firm is worse off than it really is! Of course, too often the headlines suggest firms have actually tried just the opposite-overstating Accounts Receivables (and/or understating AFBD) in an effort to buoy up the stock price, receive needed financing, or to meet certain ratio requirements. The following section notes a few of those instances.

\section{ACCOUNTS RECEIVABLE IN THE NEWS AND LITERATURE}

While not every scandalous headline highlights firms that have misrepresented receivables, many do involve a favorite approach to reporting fictitiously high income-overstating revenues, which often is accompanied by accounts receivable that are overly optimistic or even phantom. Among the most memorable of the fraudulent accounts receivable/revenue scandal headlines was the ZZZZ Best case. Young entrepreneur Barry Minkow, once dubbed the "Wonder Boy of Wall Street," created fraudulent sales and receivables for his carpet cleaning service that resulted in a firm valued at over $\$ 350$ million but which ultimately sold for less than $\$ 60,000 .{ }^{1}$ Though the Enron story accents the abuse of Special Purpose Entities and the associated beyond-GAAP reporting, it too was guilty of inappropriate financial reporting related to both sales and receivables. Not only did it overstate these items for energy contracts (by reporting the gross amount of the contracts it brokered for buyers and sellers rather than the more appropriate commissions earned by Enron), but it also misestimated future contract values using in-house models in an effort to boost bonuses and the company's stock price. Lest you believe these types of misstatements are unique to U.S. firms, a Canadian firm is highlighted in Wells [2004], and European companies have joined the party as well. ${ }^{2}$

A more common scenario occurs when firms simply accelerate revenues and receivables, typically in an effort to bolster earnings to meet analyst forecasts. Sunbeam, for example, exercised a "bill and hold" strategy (See Spiceland, p. 330.) whereby they sold deeply discounted products to retailers before the "season" in which such sales normally took place then held the products in third-party warehouses to be delivered at a later date. Thus, the revenues and assets were moved into an earlier quarter, enhancing reported earnings and financial position for that period. ${ }^{3}$ IBM used an even more egregious set of tactics in the early nineties when they recognized revenues and

\footnotetext{
${ }^{1}$ For good synopses of this case see Marden [1997] and Wells [2001].

${ }^{2}$ The Parmalat and Royal Ahold stories stand out among these, and the European accounting profession's reaction is described in Gornick-Tomaszewski and McCarthy [2005].

${ }^{3}$ See also Laing [1998] for the result on reported earnings of other discretionary accruals.
} 
receivables when computers were simply moved to warehouses in advance of installation. The reason this could be construed as a more flagrant violation of revenue recognition is that IBM's "product" included not just the computers and installation but customer training and satisfaction. In addition, IBM promised refunds if prices dropped within a certain timeframe (a likely occurrence, making the ultimate receivable much less valuable). ${ }^{4}$

Finally, in the gamut of accounts receivable schemes, this asset can be misstated through poor estimation (intentional or otherwise) of the bad debts contra account. When accountants are given the leeway to prognosticate about future collections, this can result in bad debt expense and net realizable values that are either too high or too low. In the cases of both MCI and CFS, overstatement of accounts receivable (and understatement of bad debt expense) represented a prelude to outright fraudulent reporting. At first guilty of hiding bad debt as a temporary fix for MCI's flagging earnings, finance manager Walter Pavlo eventually turned to the criminal side, embezzling millions of dollars, barely avoiding a nervous breakdown, pleading guilty to a series of offenses, and receiving a sentence of 41 months and \$5.9 million in restitution. ${ }^{5}$ In a similar vein, Zellner [1998] tells the story of Commercial Financial Services (CFS), a company specializing in buying up delinquent credit card debt and convincing the investing public that the company could collect a whopping 30 cents on the dollar (in an industry in which the norm is 15 to 23 cents). Discovery of this overvalued asset resulted in the resignation of the chief executive officer and the rest of his board of directors and threatened the stability of this new industry. Other examples exist, ${ }^{6}$ but this should give a good idea of what can happen when good accounting/accountants go astray.

Empirical studies in the area of accounts receivable are less common. One seminal article for using accounting data to determine the quality of earnings [Lev and Thiagarajan, 1993] looks at both accounts receivable and the provision for bad debts in judging the quality of earnings. The authors find that disproportionate increases in accounts receivable (relative to sales) are related to future earnings decreases, while the provision for bad debts offers no significant explanatory power for judging earnings persistence. Most empirical studies address the more general topic of earnings management and manipulation. Among the best of such articles are Rosner's 2003 study "Earnings Manipulation in Failing Firms" and Beneish [1999]. The first investigates whether failing firms are motivated to use fraudulent reporting to disguise their financial woes. The author finds that significantly greater (material) increases in accounts receivable (in comparison to control, non-distressed firms) occur, suggesting that the misstatement of receivables is used to cover up financial distress. In like fashion, Beneish discovers significant accounts receivable overstatement in a study of earnings manipulation in a set of firms over the 1982 to 1988 period. A third empirical study by McNichols and Wilson [1988] looks specifically at the use of the bad debts provision for disguising true earnings patterns, finding that firms on the verge of failure use this adjustment significantly more often than firms on more solid financial footing.

So what are the remedies for the manipulation dilemma? A guest editorial by Robert Sterling in a 2003 issue of Abacus recommends that receivables be recorded at market value (rather than at the face or "gross" amount); still estimation would be involved, both at the time the receivable is brought onto the books and again at the financial statement date. Wells [2004] offers a good roadmap for spotting fraud, but he offers no recommendation for preventing it, and Sarbanes-Oxley certainly addresses the problem in a more general way, making executives more cognizant of their responsibility for checking the reported receivables for accuracy.

\section{THIS SERIES CONTINUES}

This article provided the second installment in a series of brief articles designed to connect the theoretical constructs of the conceptual framework to the various accounting elements. It offered insights into the asset Accounts Receivable, looked at some headline stories, and listed a few approachable articles addressing the measurement issues surrounding receivables. The next installment in the series will look at the prime concerns accountants face as they measure and report inventory, another source of accounting scandals in recent years.

\footnotetext{
${ }^{4}$ The range of shenanigans IBM used is cited in Miller [1993].

${ }^{5}$ For the full story, see Levinsohn [2005].

${ }^{6}$ See Wang et al [1997] and "Weinstein's Woes" [1998] for good, short cases.
} 


\section{REFERENCES}

1. Beneish, Messod D. 1999. The Detection of Earnings Manipulation. Financial Analysts Journal. Vol. 55, Issue 5: 24-36.

2. Financial Accounting Standards Board. 1980. Qualitative Characteristics of Accounting Information. Statement of Financial Accounting Concepts No. 2. Stamford, Conn.

3. Gornik-Tomaszewski, Sylwia and Irene N. McCarthy. 2005. Response to Corporate Fraud in the United States and Europe: Towards a Consistent Approach to Regulation. Review of Business. Vol. 26, Issue 2: 1523.

4. Kieso, Donald E., Jerry J. Weygandt, and Terry D. Warfield. 2003. Fundamentals of Intermediate Accounting. United States: John Wiley \& Sons, Inc.

5. Laux, Judith A. 2007. Accounting Issues: An Essay Series Part I-Introduction to Accounting Theory and Cash. Journal of College Teaching \& Learning, Vol. 4, No. 1.

6. Lev, Baruch and S. Ramu Thiagarajan. 1993. Fundamental Information Analysis. Journal of Accounting Research. Vol. 31, No. 2 (Autumn): 190-215.

7. Levinsohn, Alan. 2005. A Cautionary Tale of Corporate Crime. Strategic Finance. Vol. 87, Issue 3: 59-60.

8. $\quad$ Liang, Jonathan. 1998. Dangerous Games. Barron's. June 8, 1998.

9. Linn, Erik and Kori Diehl. 2005. Financial Restatements: Causes, Consequences, and Corrections. Strategic Finance. Vol. 87, Issue 3: 35-39.

10. Marden, Ron. 1997. Why Receivables are Wonderful Things. National Public Accountant. Vol. 42, Issue 1: 10.

11. McNichols, Maureen and G. Peter Wilson. 1988. Evidence of Earnings Management From the Provision for Bad Debts. Journal of Accounting Research. Vol. 26, Issue 3 Supplement: 1-31.

12. Miller, Michael. 1993. As IBM's Woes Grew, Its Accounting Tactics Got Less Conservative. The Wall Street Journal. April 7, 1993.

13. Rosner, Rebecca L. 2003. Earnings Management in Failing Firms. Contemporary Accounting Research. Vol. 20, Issue 2: 361-408.

14. Spiceland, J. David; James F. Sepe, and Lawrence A. Tomassini. 2007. Intermediate Accounting, $4^{\text {th }}$ ed. McGraw-Hill.

15. Sterling, Robert R. 2003. A Patch on GAAP. Abacus. Vol. 39, No. 3: i-vi.

16. Wang, Zhemin (Jamie), Kenton D. Swift, Michael Garrison, Wayne Schmaltz, Janice Glatt, and Paulette Letnes. 1997. AICPA Case Development Program. Case No. 96-07.

17. Weinstein's Woes: How a $\$ 90$ million Company Went Broke. 1998. Fraud Magazine, Vol. 12, No. 1: 1921.

18. Wells, Joseph T. 2001. Irrational Ratios. Journal of Accountancy. Vol. 192, Issue 2: 80-83.

19. 2004. The Quarter-Million-Dollar Caper. Journal of Accountancy. Vol. 198, Issue 5: 89-91.

20. Zellner, Wendy. 1998. How CFS Made Bad Debts Pay So Well. Business Week. Issue 3603 (Nov. 9, 1998): 48. 